\title{
Differences in arterial stiffness at rest and after acute exercise between young men and women
}

\author{
Robert J Doonan, Andrew Mutter, Giordano Egiziano, Yessica-Haydee Gomez and Stella S Daskalopoulou \\ There is controversy as to whether there are sex differences in arterial stiffness. Acute physical stress can elicit vascular \\ abnormalities not present at rest. Our objective was to assess sex differences in arterial stiffness at rest and in response to \\ acute physical stress. Healthy young men $(n=67)$ and women $(n=55)$ underwent pulse wave analysis and carotid-femoral \\ pulse wave velocity measurements at rest and 2, 5, 10 and $15 \mathrm{~min}$ following an exercise test to exhaustion. At rest, aortic \\ systolic, diastolic, pulse and mean pressures were all significantly higher in men as was aortic pulse pressure at 10 and 15 min \\ post exercise and aortic systolic pressure at $15 \mathrm{~min}$. Carotid-femoral pulse wave velocity was significantly higher in men \\ $\left(6.0 \pm 0.7 \mathrm{~m} \mathrm{~s}^{-1}\right.$ vs. $\left.5.6 \pm 0.6 \mathrm{~m} \mathrm{~s}^{-1}, P=0.03\right)$ at rest and at all time points post exercise. Heart rate-adjusted augmentation \\ index was significantly lower $(-10.7 \pm 10.2 \%$ vs. $-4.0 \pm 10.9, P<0.0001)$ and subendocardial viability ratio was significantly \\ higher $(176.2 \pm 43.8 \%$ vs. $163.4 \pm 40.9, P=0.04)$ in men at rest. To our knowledge, this is the first study to assess sex \\ differences in the arterial stiffness response to acute physical stress in young men and women. Although we were not able to \\ elicit differences in vascular function after adjustment, which were not present at rest, we found that young men and women \\ exhibit differences in arterial stiffness at rest and after acute physical stress.
}

Hypertension Research (2013) 36, 226-231; doi:10.1038/hr.2012.158; published online 11 October 2012

Keywords: augmentation index; exercise testing; pulse wave velocity; sex differences; subendocardial viability ratio

\section{INTRODUCTION}

Cardiovascular diseases (CVD) are the leading cause of mortality worldwide. ${ }^{1}$ It has been extensively demonstrated that CVD affect men and women differently. According to the American Heart Association, the prevalence of CVD is $15.9 \%$ in young men, and $7.8 \%$ in young women aged $20-39$ years, $37.9 \%$ and $38.5 \%$ for ages $40-59$ years, respectively, and up to $79.3 \%$ and $85.9 \%$ for men and women over age 80 years, respectively. ${ }^{2}$ These data indicate a higher prevalence for CVD in men below the age of 40 , with advancing age leading to a gradual attenuation and reversal in this trend.

It is clear that there are inherent sex differences related to CVD at all age levels, but the underlying mechanisms that explain these differences remain unclear. It is well documented that arterial stiffness increases with age in both men and women. ${ }^{3-6}$ Whereas several studies have reported similar changes in arterial stiffness for both sexes with advancing age, ${ }^{7}$ others have demonstrated sex-related differences in arterial stiffness. ${ }^{3,4,8}$ Most of these previous studies have been carried out on older age groups or wide age ranges, and have assessed arterial stiffness only at rest. We have previously shown that it is possible to unmask vascular abnormalities that were not present at rest using acute physical stress with a protocol we have termed, 'the arterial stress test.' Therefore, the objective of the current study was to investigate differences in arterial stiffness and hemodynamic parameters in young healthy men and women at rest and after acute physical stress. We hypothesized that there are differences in arterial stiffness and hemodynamics between young men and women at rest and post exercise.

\section{METHODS}

Participants

We recruited consecutive healthy men and women via local advertisements and within the McGill University Health Centre Community. Exclusion criteria were previously diagnosed CVD, including congenital heart diseases, traditional cardiovascular risk factors (including diabetes mellitus, hypertension, dyslipidemia and the metabolic syndrome), renal disease, respiratory diseases, inflammatory diseases (that is, rheumatoid arthritis, systemic vasculitis, systemic lupus erythematosus), obesity (body mass index, BMI $\geqslant 30 \mathrm{~kg} \mathrm{~m}^{-2}$ ), pregnancy and history of smoking. Furthermore, participants who were acutely ill (that is febrile), on cardioprotective medications or women on oral contraceptives were not eligible to participate in this study. As there is conflicting evidence that different phases of the menstrual cycle can affect arterial stiffness, ${ }^{10-12}$ women were examined during the early follicular phase of the menstrual cycle to minimize this possibility. The phase was ascertained by directly querying the cycle length and date of the start of the last menses. This study was approved by the ethics and scientific review boards of the McGill University Health Centre. Written informed consent was obtained for all participants. 
Information about past medical history, current medication use, smoking history (ever smokers were excluded) and physical activity levels were directly queried. Participants were grouped into low, medium and high activity levels according to the International Physical Activity Questionnaire guidelines. ${ }^{13}$

Height and weight were measured and BMI $\left(\mathrm{kg} \mathrm{m}^{-2}\right)$ was calculated. Before undergoing the arterial stress test, participants were asked to abstain from all caffeine-containing beverages and ethanol intake for at least $12 \mathrm{~h}$, and from strenuous exercise for $24 \mathrm{~h}$ before the assessment. All assessments were performed at the same time of the day throughout the study to reduce circadian variations. ${ }^{14}$

\section{Arterial stiffness measurements}

Pulse wave analysis (PWA) and carotid-femoral pulse wave velocity (cfPWV) measurements were performed using applanation tonometry (SphygmoCor, AtCor Medical, Sydney, NSW, Australia). PWA was used to determine the augmentation index (AIx), subendocardial viability ratio (SEVR) and aortic blood pressures (BPs). SEVR is calculated as area under the curve (AUC) during diastole/AUC during systole. An average radial pressure waveform was generated from $10 \mathrm{~s}$ of sequential radial pressure waveforms. Using a previously validated generalized transfer function, the SphygmoCor system software calculated an averaged radial artery waveform (calibrated with peripheral systolic and diastolic BPs) and derived a corresponding aortic pressure waveform (as well as the aortic pressure and the AIx75, a heart rate (HR)adjusted AIx and SEVR). ${ }^{15,16}$ The cfPWV was measured using applanation tonometry in combination with a three-lead electrocardiography. CfPWV is automatically calculated from measurements of the pulse transit time and the distance between the two recording sites, carotid and femoral (PWV $=$ distance $(\mathrm{m}) /$ transit time $(\mathrm{s}))^{17}$

\section{Arterial stress test protocol}

After $10 \mathrm{~min}$ of rest in a supine position in a temperature- $\left(22 \pm 1^{\circ} \mathrm{C}\right)$ and humidity- $(60 \pm 5 \%)$ controlled environment, brachial BP, PWA and cfPWV measurements were performed. ${ }^{9}$ Brachial BP was measured according to the Canadian Hypertension Education Program guidelines ${ }^{18,19}$ in triplicate using cuff sphygmomanometry (HEM-705CP, Omron Corp., Kyoto, Japan). The average of the last two measurements was used. PWA and cfPWV measurements were performed in duplicate and values were averaged for analysis. The points of measurements were marked to ensure that measurements were performed on the same pulse points post exercise. To induce physical stress, participants subsequently completed a supervised incremental treadmill exercise protocol to volitional exhaustion (Bruce protocol ${ }^{20}$ ), which has been validated in young healthy individuals $;{ }^{20}$ throughout the test, HR was monitored. Participants were deemed to reach maximal exercise capacity when all three of the following criteria were met: (i) the participant could no longer continue the exercise protocol, (ii) a minimum of 19 was reached on the Borg scale, which is a subjective parameter for exercise intensity ${ }^{20}$ and (iii) the participant reached at least $90 \%$ of their age-predicted maximum HR (objective parameter for exercise intensity). Time to exercise completion was recorded.

Immediately post exercise, participants rested in a supine position. At $2 \mathrm{~min}$ post exercise, cfPWV was assessed once and at 5,10 and 15 min post-exercise cfPWV and PWA measurements were each performed once, in that order. Brachial BP was measured at the same time points as arterial stiffness measurements in the contralateral arm, after confirmation of absence of difference in BP between the two arms at rest $(<5 / 3 \mathrm{~mm} \mathrm{Hg}$ for systolic and diastolic BP). ${ }^{21}$ All measurements were in accordance with the Sphygmocor internal quality control system to accomplish a quality index $>85 \% .{ }^{22,23}$ The above-mentioned protocol constitutes the 'arterial stress test.'

\section{Determination of peak metabolic equivalents (METs)}

Peak $\mathrm{VO}_{2}$ was calculated as: $\mathrm{VO}_{2}$ peak $=0.2$ (speed) +0.9 (speed $\times$ grade of treadmill), where speed is in $\mathrm{m} \mathrm{min}^{-1} .{ }^{24}$ Peak METs was then calculated by dividing the calculated $\mathrm{VO}_{2}$ peak by the resting metabolic rate $(1 \mathrm{MET})$ of each individual participant calculated by the Harris-Benedict equation: ${ }^{25}$ male $=66.4730+5.0033$ (height, $\mathrm{cm})+13.7516$ (weight, $\mathrm{kg}$ ) -6.7550 (age, years); female $=655.0955+1.8496$ (height, $\mathrm{cm})+9.5634$ (weight, $\mathrm{kg})-4.6756$ (age, years)

\section{Statistical analysis}

SAS version 9.2 software (SAS Institute, Cary, NC, USA) was used for all statistical analyses. Demographic and baseline characteristics of men and women were compared using chi-squared test and independent $t$-tests for categorical and continuous variables, respectively, after assessing the distribution of continuous variables using normal probability plots. Comparisons between men and women of resting parameters were performed using general linear models without and with adjustment. Resting mean arterial pressure (MAP), aortic systolic BP (SBP), aortic diastolic BP (DBP) and aortic pulse pressure (PP) were adjusted for age and BMI, whereas all the other parameters were adjusted for age, BMI and resting MAP using analysis of covariance (ANCOVA). Post-exercise and post-pre exercise changes (= greatest postexercise value -resting value) between-group comparisons for BPs were performed in a similar manner but with and without adjustment for age, BMI, peak METs and the corresponding resting BP parameter. All other parameters were adjusted for age, BMI, resting MAP, peak METs and the resting value of the parameter of interest.

\section{RESULTS}

\section{Participant characteristics}

We recruited 122 subjects; 67 men and 55 women. Participant characteristics, resting peripheral BPs and exercise parameters are available in Table 1. Figures $1 \mathrm{a}-\mathrm{d}$ and $2 \mathrm{a}-\mathrm{d}$ and Supplementary Table 1 contain resting and post-exercise arterial hemodynamic parameters. Table 2 contains post-pre exercise changes. All subjects reached maximal exercise capacity according to the pre-specified criteria mentioned above.

\section{Arterial stiffness and hemodynamic parameters}

HR was not significantly different between groups at rest and $2 \mathrm{~min}$ post exercise (Table 1 and Supplementary Table 1). However, at 5, 10 and $15 \mathrm{~min}$ after exercise, HR was significantly higher in men. Maximum HR post exercise was 193.5 beats per min in men and 186.2 in women, which corresponds to $98.9 \%$ and $94.9 \%$ of the estimated maximum HR for men and women, respectively. Aortic SBP, DBP and PP, as well as MAP were all significantly higher in men at rest after adjustment for age and BMI. Post-exercise aortic SBP was significantly higher in men at each time point. However, this lost significance after adjustment at 5 and $10 \mathrm{~min}$. Aortic PP was also significantly higher in men at 5,10 and $15 \mathrm{~min}$ post exercise before adjustment, and at 10 and $15 \mathrm{~min}$ after adjustment.

Table 1 Baseline participant characteristics and exercise parameters

\begin{tabular}{lrrc}
\hline & Men $(\mathrm{n}=67)$ & Women $(\mathrm{n}=55)$ & P-value \\
\hline Age (years) & $24.4 \pm 6.2$ & $23.7 \pm 4.8$ & n.s. \\
Height (cm) & $176.8 \pm 6.3$ & $163.6 \pm 8.2$ & $<0.0001$ \\
Weight (kg) & $71.5 \pm 9.4$ & $58.1 \pm 7.9$ & $<0.0001$ \\
BMI (kg m ${ }^{-2}$ ) & $22.8 \pm 2.7$ & $21.7 \pm 2.1$ & 0.009 \\
Resting peripheral SBP (mm Hg) & $114.2 \pm 9.8$ & $103.1 \pm 6.7$ & $<0.0001$ \\
Resting peripheral DBP (mm Hg) & $69.7 \pm 8.2$ & $65.3 \pm 5.6$ & 0.001 \\
Resting peripheral PP (mm Hg) & $44.4 \pm 8.3$ & $37.8 \pm 6.2$ & $<0.0001$ \\
Resting HR (beats per min) & $62.4 \pm 9.5$ & $63.4 \pm 9.4$ & n.s. \\
Max exercise time (min) & $16.2 \pm 1.8$ & $14.2 \pm 1.2$ & $<0.0001$ \\
Max METs & $14.8 \pm 1.6$ & $13.6 \pm 1.6$ & $<0.0001$ \\
Max HR (beats per min) & $193.5 \pm 9.7$ & $186.2 \pm 10.1$ & 0.0002 \\
Physical activity-low, $n(\%)$ & $12(17.9)$ & $13(23.6)$ & n.s. \\
Physical activity-moderate, $n(\%)$ & $33(49.3)$ & $26(47.3)$ & n.s. \\
Physical activity-high, $n(\%)$ & $22(32.8)$ & $16(29.1)$ & n.s. \\
\hline
\end{tabular}

Abbreviations: BMI, body mass index; DBP, diastolic blood pressure; HR, heart rate; max, maximum; MET, metabolic equivalent; n.s., not significant; PP, pulse pressure; SBP, systolic blood pressure.

All values are mean \pm s.d. 

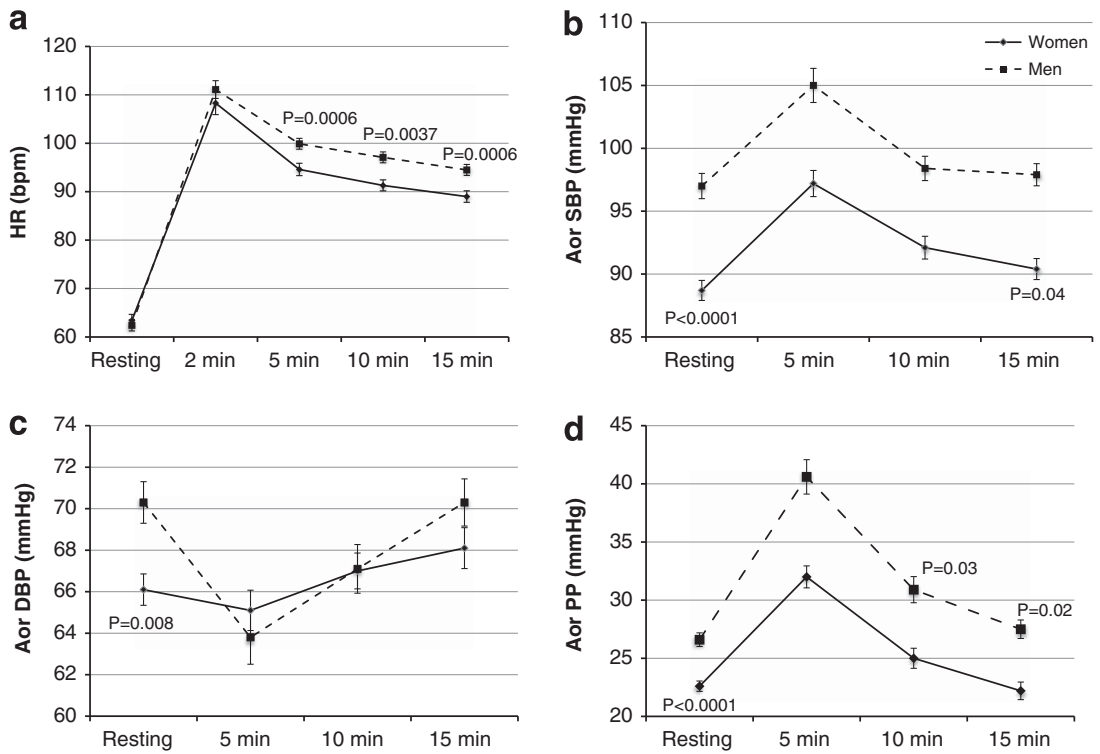

Figure 1 Vessel hemodynamic parameters in men and women at rest and post-exercise. (a) heart rate (HR), (b) aortic systolic pressure (Aor SBP), (c) aortic diastolic pressure (Aor DBP) and (d) aortic pulse pressure (Aor PP) are presented. Presented as mean \pm s.e. P-values are adjusted.
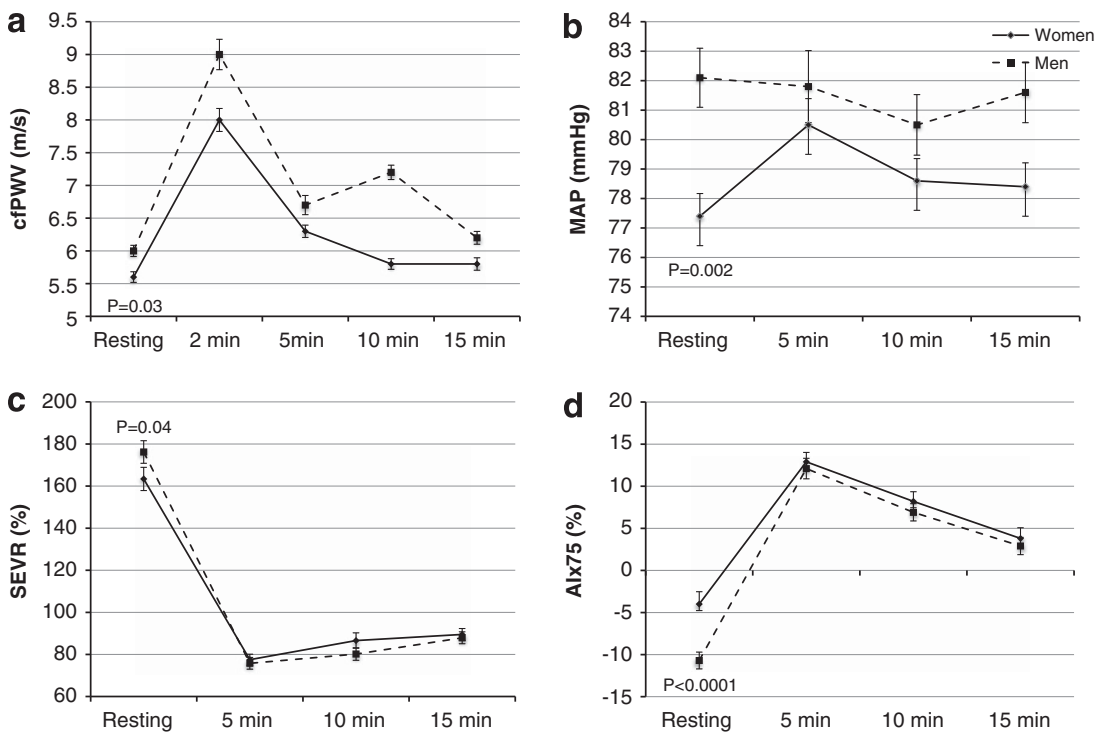

Figure 2 Arterial stiffness and vessel hemodynamic parameters in men and women at rest and post exercise. (a) Carotid-femoral pulse wave velocity (cfPWV), (b) mean arterial pressure (MAP), (c) subendocardial viability ratio (SEVR) and (d) heart rate-adjusted augmentation index (Alx75) are presented. Presented as mean \pm s.e. $P$-values are adjusted.

Differences between men and women with respect to aortic DBP were non-significant post exercise, and MAP was only significantly higher in men at 15 min without adjustment.

cfPWV was significantly higher in men at rest after adjustment (Figure 2a and Supplementary Table 1). Post-exercise cfPWV was also higher in men at all time points but this lost significance after adjustment for age, BMI, peak METs, resting MAP and resting cfPWV. AIx75 was significantly lower and SEVR was significantly higher in men at rest after adjustment. When height was added to the adjusted AIx75 model, significance was lost. No significant differences were found post exercise for AIx75 or SEVR.

Post-pre exercise changes were calculated (Table 2). We found that men had a greater decrease in aortic DBP, MAP and SEVR and a greater increase in aortic PP, cfPWV and AIx75. However, significance was lost after adjustment for all these parameters, except for aortic DBP.

\section{DISCUSSION}

To our knowledge, this is the first study to assess sex differences in the arterial stiffness and arterial hemodynamics at rest and in response to acute physical stress in young men and women. Using 'the arterial stress test', we found that men and women exhibit not only differences in arterial stiffness at rest but also after acute physical stress.

cfPWV is considered to be the 'gold standard' in the assessment of arterial stiffness, as it represents the stiffness of the aorta. ${ }^{26,27}$ Therefore, an important finding is that young men have increased 
Table 2 Post-pre exercise changes

\begin{tabular}{|c|c|c|c|}
\hline & $\begin{array}{l}\text { Post-pre } \\
\text { exercise } \\
\text { change }\end{array}$ & $\begin{array}{c}\text { Adjusted } \\
\text { P-value }\end{array}$ & $\begin{array}{c}\text { Unadjusted } \\
\text { P-value }\end{array}$ \\
\hline \multicolumn{4}{|c|}{$H R$ (beats per min) } \\
\hline Women & $44.7 \pm 16.6$ & n.s. & n.s. \\
\hline Men & $48.7 \pm 15.6$ & & \\
\hline \multicolumn{4}{|c|}{ Aor SBP $(\mathrm{mm} \mathrm{Hg})$} \\
\hline Women & $8.4 \pm 7.0$ & n.s. & n.s. \\
\hline Men & $7.7 \pm 8.5$ & & \\
\hline \multicolumn{4}{|c|}{ Aor DBP $(\mathrm{mm} \mathrm{Hg})$} \\
\hline Women & $-1.1 \pm 8.2$ & 0.02 & 0.0006 \\
\hline Men & $-6.7 \pm 8.9$ & & \\
\hline \multicolumn{4}{|c|}{ Aortic PP ( $\mathrm{mm} \mathrm{Hg})$} \\
\hline Women & $9.5 \pm 6.5$ & n.s. & 0.01 \\
\hline Men & $13.9 \pm 10.6$ & & \\
\hline \multicolumn{4}{|c|}{ MAP $(m m H g)$} \\
\hline Women & $3.0 \pm 6.8$ & n.s. & 0.01 \\
\hline Men & $-0.54 \pm 8.1$ & & \\
\hline \multicolumn{4}{|c|}{$c f P W V\left(m s^{-1}\right)$} \\
\hline Women & $2.4 \pm 1.1$ & n.s. & 0.03 \\
\hline Men & $3.0 \pm 1.7$ & & \\
\hline \multicolumn{4}{|l|}{ Alx75 (\%) } \\
\hline Women & $17.2 \pm 10.1$ & n.s. ${ }^{a}$ & 0.007 \\
\hline Men & $22.9 \pm 11.4$ & & \\
\hline \multicolumn{4}{|l|}{ SEVR (\%) } \\
\hline Women & $-85.9 \pm 32.6$ & n.s. & 0.05 \\
\hline Men & $-100.7 \pm 47.8$ & & \\
\hline
\end{tabular}

Abbreviations: Alx75, augmentation index adjusted to heart rate of 75 beats per minute; Aor, aortic; cfPWV, carotid-femoral pulse wave velocity; DBP, diastolic blood pressure; HR, heart rate; MAP, mean arterial pressure; n.s., not significant; PP, pulse pressure; SBP, systolic blood pressure; SEVR, subendocardial viability ratio.

cfPWV and HR post-pre exercise changes were calculated as the difference between the parameter at $2 \mathrm{~min}$ post exercise and at rest. All other parameters were calculated as the difference between the paramater at $5 \mathrm{~min}$ post exercise and at rest. difference between the param

a $P=$ n.s. after adjustment for height.
.

cfPWV at rest and after acute physical stress compared with women (Figure 2a and Supplementary Table 1). The pathophysiological explanation for this is unclear. However, differences in hormone and endothelin-1 (ET-1) production between men and women could contribute to the increased cfPWV seen in men. Estrogens decrease vascular resistance, improve endothelial dysfunction and decrease $\mathrm{BP}^{28}$ Indeed, it has been previously shown that the increased estrogen concentrations found in women is associated with reduced aortic stiffness. $^{29}$ Pearson et al. ${ }^{30}$ found that testosterone induces upregulation of endothelin-1 mRNA in human aortic endothelial cells and an increase in the number of ET-1-secreting cells, whereas Stauffer et al. found than men are under greater ET-1 receptor tone than age-matched women. ${ }^{31}$ Furthermore, ET-1 has been shown to be associated with arterial stiffness. ${ }^{32,33}$ Although we did not measure sex hormones or ET-1 in this study, it is possible that differences in estrogen, testosterone and/or ET-1 between men and women contributed to the increased cfPWV seen in men.

The previous literature is not clear with respect to sex differences in cfPWV. The Anglo-Cardiff Collaborative Trial has demonstrated that there was no significant difference in cfPWV at rest between healthy men and women. ${ }^{34}$ Other previous studies found similar results. ${ }^{7,35,36}$ While the Reference Values for Arterial Stiffness' Collaboration recently demonstrated that there were sex differences in $\mathrm{cfPWV}$, men had only $0.1 \mathrm{~m} \mathrm{~s}^{-1}$ greater cfPWV than women after adjustment for traditional cardiovascular risk factors. ${ }^{37}$ However, many studies also have found sex differences in aortic stiffness. ${ }^{8,28,38,39}$ Aortic distensibility index and aortic impedence were higher in young men compared with women, but the reverse was true in an older population. ${ }^{8}$ Furthermore, the age-related increase in cfPWV was also greater in women than in men. ${ }^{38}$ It was noted that cfPWV is higher in middle-aged men. ${ }^{39}$ Moreover, another study measuring brachial-ankle PWV (baPWV) found that men had higher baPWV until age 60 , whereas it was similar between sexes after age $60{ }^{4}$ It is clear that the heterogeneity of previous results was due, at least partly, to the different techniques used and age ranges of participants in these studies.

In the Framingham Heart Study, a one s.d. increment in arterial stiffness, as measured by cfPWV, was associated with a $48 \%$ increase in arterial disease risk, independently of individual vascular risk factors. ${ }^{40}$ Furthermore, a meta-analysis found that an increase in cfPWV by $1 \mathrm{~m} \mathrm{~s}^{-1}$ corresponded to an age-, sex- and risk factoradjusted risk increase of $14 \%, 15 \%$ and $15 \%$ in total CV events, CV mortality and all-cause mortality, respectively. ${ }^{41}$ An increase in cfPWV by 1 s.d. was associated with respective increases of $47 \%$, $47 \%$ and $42 \%{ }^{41}$ These studies did not assess sex differences and they were performed in much older populations compared with this study. Therefore, we cannot be sure of the applicability, especially considering 1 s.d. in cfPWV in our population represents $\sim 0.7 \mathrm{~m} \mathrm{~s}^{-1}$, which is less than the $1 \mathrm{~m} \mathrm{~s}^{-1}$ and 1 s.d. used in these studies. Longitudinal studies in younger populations are needed to determine if cfPWV can be used as a marker for premature cardiovascular risk. Moreover, it is possible that using the arterial stress test may be useful to unmask further differences in vascular function. Longitudinal studies are needed to establish if this difference in response to acute physical stress is associated with the greater premature CVD seen in men.

It is also interesting that men showed an increased cfPWV after exercise despite a concomitant decrease in MAP (Figure 2a, Table 2 and Supplementary Table 1) even though it is well established that cfPWV and MAP are positively correlated. ${ }^{42}$ It has been shown that nitric oxide $(\mathrm{NO})$ synthase activity correlates to exercise capacity ${ }^{43}$ and that decreased NO synthesis is associated with increased arterial stiffness. ${ }^{44}$ Therefore, as men achieved higher workloads (greater exercise time, maximum $\mathrm{HR}$ and maximum METs), it is possible that an increase in NO synthesis was responsible for the decrease in MAP, which may underestimate the differences in cfPWV between groups.

We also found that at rest, women have higher AIx75. These findings agree with previous studies. ${ }^{35,45,46}$ A significantly higher AIx, which represents systemic wave reflection, was noted in women above the age of 30 compared with age-matched men, with a similar trend between the ages of 10 and 29 years. ${ }^{45}$ Furthermore, significantly higher AIx in women than men was previously found, even after adjustment for age, HR and MAP. ${ }^{35,46}$ However, women have smaller body height at all ages, and this was shown to also be true in our study population $(P<0.0001)$. This has been hypothesized to cause earlier wave reflection resulting in an increased AIx. Indeed, in our population, when height was added to the adjusted model, significance was lost. Others have also found that after adjusting for height, sex differences in AIx are lost. ${ }^{35,46}$ However, in a group of elderly hypertensive men and women, a significantly elevated AIx was noted in women $(P<0.001)$ even though the groups were matched for height. ${ }^{47}$ It was also found that prepubescent women had a significantly greater AIx than men of similar age and height. ${ }^{48}$ Therefore, it appears that although some sex differences in AIx can 
be attributed to differences in height, it may not be the only contributor. Along those lines, it has also been shown that part of the increased AIx in women may be due to increased tapering of arterial diameter from the aorta to the periphery, which increases wave reflections. ${ }^{49}$

We found that men have higher aortic PP both pre- and postexercise and that their post-pre exercise change of SEVR was significantly lower (greater decrease) than women before adjustment. The difference in aortic PP is expected and is in line with the fact that men have higher stroke volumes and body sizes. ${ }^{50,51}$ As men achieved higher workloads (greater exercise time, maximum $\mathrm{HR}$ and maximum METs), they also likely achieved higher cardiac outputs and stroke volumes post exercise, which may explain the increased aortic PP in men post exercise. As the lowest SEVR achieved at $5 \mathrm{~min}$ post exercise was relatively similar in men and women (men, $75.8 \pm 22.8$; women, $77.5 \pm 19.5, P=$ n.s.), the difference in post-pre exercise change was due to the resting differences (men, 176.2 \pm 43.8 ; women, $163.4 \pm 40.9, P=0.04)$. As SEVR represents cardiac $\mathrm{O}_{2}$ supply/demand ratio, ${ }^{52,53}$ our results suggest that young healthy men have a greater reserve, which may explain in part the fact that men were able to achieve higher workloads. Though we cannot be certain if men achieved greater workloads because they have a greater reserve or if men appear to have a greater reserve because they achieved higher workloads. In line with these results, others noted that men have higher SEVR at all ages from the first to the seventh decade. ${ }^{45}$ Another study found that men have higher SEVR in a group with mean age in their 40s. ${ }^{54}$

Using the arterial stress test, we were not able to elicit differences between men and women in arterial stiffness that were not already present at rest. We have previously shown that in very light smokers who are otherwise healthy, acute physical stress can elicit vascular abnormalities that were not present at rest. ${ }^{9}$ However, here we noted that differences in $\mathrm{CfPWV}$, aortic BPs, AIx and SEVR between men and women existed already at rest.

There are limitations to this study. As we recruited consecutive participants who responded to our advertisements, we were not able to match for age and height. However, we did adjust for these covariates as well as others. In fact, to take a conservative approach, we adjusted more extensively than many other studies are able to, as we have a relatively large sample size. Because of the technical limitations of applanation tonometry, we were not able to measure arterial stiffness throughout exercise, only immediately post exercise. However, this is the most important information, as we needed to measure the ability of the vascular system to respond to maximal physical stress in men and women. Furthermore, as the time limitations for measurements post exercise were strict, we did not perform the PWA analysis at $2 \mathrm{~min}$. We also did not measure $\mathrm{VO}_{2 \max }$ to confirm that the subjects reached their maximal exercise capacity. However, $\mathrm{VO}_{2}$ peak was calculated using a validated formula from the American College of Sports Medicine (ACSM) ${ }^{24}$ and we used three well-established criteria to ensure our subjects reached maximal exercise capacity, as mentioned in the Methods section. ${ }^{20}$ Moreover, men reached a greater workload (greater exercise time, maximum HR and maximum METs) than women making direct comparisons for some arterial stiffness parameters difficult to interpret.

\section{CONCLUSION}

We have shown for the first time using 'the arterial stress test' that young men and women exhibit differences not only in arterial stiffness at rest but also after acute physical stress. Using the arterial stress test, we confirmed differences in vascular function that were present at rest but did not elicit further differences. This is likely because sex differences at rest were already present in cfPWV, aortic BPs, AIx and SEVR. Further longitudinal studies need to determine whether these sex differences seen in young populations are associated with cardiovascular risk differences seen later in life between men and women.

\section{CONFLICT OF INTEREST}

The authors declare no conflict of interest.

\section{ACKNOWLEDGEMENTS}

This study was funded by a grant from the Canadian Institutes of Health Research (MOP\#102626). Dr Stella S Daskalopoulou (Chercheur-Boursier Clinicien) is supported by the Fonds de la recherche en sante du Québec. Robert-James Doonan is supported by a Canadian Institutes of Health Research MD-PhD studentship.

1 World Health Organization (WHO). Annex Table 2: Deaths by Cause, Sex, and Mortality Stratum in WHO Regions, Estimates for 2002 WHO, Geneva, 2004.

2 Lloyd-Jones D, Adams R, Carnethon M, De Simone D, Fergusion TB, Furie K, Go A, Greenlund K, Haase N. Heart disease and stroke statistics-2009 update: a report from the American Heart Association Statistics Committee and Stroke Statistics Subcommittee. Circulation 2008; 119: e21-181.

3 Mitchell GF, Parise H, Benjamin EJ, Larson MG, Keyes MJ, Vita JA, Vasan RS, Levy D. Changes in arterial stiffness and wave reflection with advancing age in healthy men and women: the Framingham Heart Study. Hypertension 2004; 43: 1239-1245.

4 Tomiyama H, Yamashina A, Arai T, Hirose K, Koji Y, Chikamori T, Hori S, Yamamoto Y, Doba N, Hinohara S. Influences of age and gender on results of noninvasive brachialankle pulse wave velocity measurement-a survey of 12517 subjects. Atherosclerosis 2003; 166: 303-309.

5 De AL, Millasseau SC, Smith A, Viberti G, Jones RH, Ritter JM, Chowienczyk PJ. Sex differences in age-related stiffening of the aorta in subjects with type 2 diabetes. Hypertension 2004; 44: 67-71

6 Zaydun G, Tomiyama H, Hashimoto H, Arai T, Koji Y, Yambe M, Motobe K, Hori S, Yamashina A. Menopause is an independent factor augmenting the age-related increase in arterial stiffness in the early postmenopausal phase. Atherosclerosis 2006; 184: 137-142.

7 Smulyan H, Asmar RG, Rudnicki A, London GM, Safar ME. Comparative effects of aging in men and women on the properties of the arterial tree. J Am Coll Cardiol 2001; 37: $1374-1380$.

8 Waddell TK, Dart AM, Gatzka CD, Cameron JD, Kingwell BA. Women exhibit a greater age-related increase in proximal aortic stiffness than men. J Hypertens 2001; 19: 2205-2212.

9 Doonan RJ, Scheffler P, Yu A, Egiziano G, Mutter A, Bacon S, Carli F, Daskalopoulos $\mathrm{ME}$, Daskalopoulou SS. Altered arterial stiffness and subendocardial viability ratio in young healthy light smokers after acute exercise. PLoS One 2011; 6: e26151.

10 Ounis-Skali N, Mitchell GF, Solomon CG, Solomon SD, Seely EW. Changes in central arterial pressure waveforms during the normal menstrual cycle. J Invest Med 2006; 54: 321-326.

11 Hayashi K, Miyachi M, Seno N, Takahashi K, Yamazaki K, Sugawara J, Yokoi T, Onodera $\mathrm{S}$, Mesaki N. Variations in carotid arterial compliance during the menstrual cycle in young women. Exp Physiol 2006; 91: 465-472.

12 Papaioannou TG, Stamatelopoulos KS, Georgiopoulos G, Vlachopoulos C, Georgiou S, Lykka M, Lambrinoudaki I, Papamichael CM, Stefanadis Cl. Arterial wave reflections during the menstrual cycle of healthy women: a reproducibility study. Hypertension 2009; 54: 1021-1027.

13 International Physical Activity Questionnaire 2002 (www.ipaq.ki.se).

14 Papaioannou TG, Karatzis EN, Papamichael CM, Karatzi KN, Zakopoulos NA, Lekakis JP, Mavrikakis M, Stefanadis $\mathrm{C}$. Circadian variation of arterial pressure wave reflections. Am J Hypertens 2006; 19: 259-263.

15 Chen CH, Nevo E, Fetics B, Pak PH, Yin FC, Maughan WL, Kass DA. Estimation of central aortic pressure waveform by mathematical transformation of radial tonometry pressure. Validation of generalized transfer function. Circulation 1997; 95: 1827-1836.

16 Pauca AL, O'Rourke MF, Kon ND. Prospective evaluation of a method for estimating ascending aortic pressure from the radial artery pressure waveform. Hypertension 2001; 38: 932-937.

17 Van Bortel LM, Duprez D, Starmans-Kool MJ, Safar ME, Giannattasio C, Cockcroft J, Kaiser DR, Thuillez C. Clinical applications of arterial stiffness, Task Force III: recommendations for user procedures. Am J Hypertens 2002; 15: 445-452.

18 Rabi DM, Daskalopoulou SS, Padwal RS, Khan NA, Grover SA, Hackam DG, Myers MG McKay DW, Quinn RR, Hemmelgarn BR, Cloutier L, Bolli P, Hill MD, Wilson T, Penner B, Burgess E, Lamarre-Cliche M, McLean D, Schiffrin EL, Honos G, Mann K, Tremblay G, Milot A, Chockalingam A, Rabkin SW, Dawes M, Touyz RM, Burns KD, Ruzicka M Campbell NR, Vallee M, Prasad GV, Lebel M, Campbell TS, Lindsay MP, Herman RJ, 
Larochelle P, Feldman RD, Arnold JM, Moe GW, Howlett JG, Trudeau L, Bacon SL, Petrella RJ, Lewanczuk R, Stone JA, Drouin D, Boulanger JM, Sharma M, Hamet $P$, Fodor G, Dresser GK, Carruthers SG, Pylypchuk G, Gilbert RE, Leiter LA, Jones C, Ogilvie RI, Woo V, McFarlane PA, Hegele RA, Poirier L, Tobe SW. The 2011 canadian hypertension education program recommendations for the management of hypertension: blood pressure measurement, diagnosis, assessment of risk, and therapy. Can J Cardiol 2011; 27: 415-433.

19 Daskalopoulou SS, Khan NA, Quinn RR, Ruzicka M, McKay DW, Hackam DG, Rabkin SW, Rabi DM, Gilbert RE, Padwal RS, Dawes M, Touyz RM, Campbell TS, Cloutier L, Grover S, Honos G, Herman RJ, Schiffrin EL, Bolli P, Wilson T, Feldman RD, Lindsay MP, Hemmelgarn BR, Hill MD, Gelfer M, Burns KD, Vallee M, Prasad GV, Lebel M, McLean D, Arnold JM, Moe GW, Howlett JG, Boulanger JM, Larochelle P, Leiter LA, Jones C, Ogilvie RI, Woo V, Kaczorowski J, Trudeau L, Bacon SL, Petrella RJ, Milot A, Stone JA, Drouin D, Lamarre-Cliche M, Godwin M, Tremblay G, Hamet P, Fodor G, Carruthers SG, Pylypchuk G, Burgess E, Lewanczuk R, Dresser GK, Penner B, Hegele RA, McFarlane PA, Sharma M, Campbell NR, Reid D, Poirier L, Tobe SW. The 2012 Canadian hypertension education program recommendations for the management of hypertension: blood pressure measurement, diagnosis, assessment of risk, and therapy. Can J Cardiol 2012; 28: 270-287.

20 Astrand P-O, Rodahl K, Dahl HA, Stromme SB. Textbook of Work Physiology: Physiological Bases of Exercise. McGraw-Hill, New York.

21 Arnett DK, Tang W, Province MA, Oberman A, Ellison RC, Morgan D, Eckfeldt JH, Hunt SC. Interarm differences in seated systolic and diastolic blood pressure: the Hypertension Genetic Epidemiology Network study. J Hypertens 2005; 23: 1141-1147

22 Smulyan H, Siddiqui DS, Carlson RJ, London GM, Safar ME. Clinical utility of aortic pulses and pressures calculated from applanated radial-artery pulses. Hypertension 2003; 42: 150-155.

23 O'Rourke MF, Pauca A, Jiang XJ. Pulse wave analysis. Br J Clin Pharmacol 2001; 51: 507-522.

24 Thompson W. ACSM's Guidelines for Exercise Testing and Prescription. Lippincott Williams \& Wilkins, New York 2009.

25 Harris JA, Benedict FG. A biometric study of human basal metabolism. Proc Natl Acad Sci USA 1918; 4: 370-373.

26 Laurent S, Cockcroft J, Van BL, Boutouyrie P, Giannattasio C, Hayoz D, Pannier B, Vlachopoulos C, Wilkinson I, Struijker-Boudier H. Expert consensus document on arterial stiffness: methodological issues and clinical applications. Eur Heart J 2006; 27: 2588-2605.

27 Mancia G, De BG, Dominiczak A, Cifkova R, Fagard R, Germano G, Grassi G, Heagerty AM, Kjeldsen SE, Laurent S, Narkiewicz K, Ruilope L, Rynkiewicz A, Schmieder RE, Struijker Boudier HA, Zanchetti A, Vahanian A, Camm J, De CR, Dean V, Dickstein K, Filippatos G, Funck-Brentano C, Hellemans I, Kristensen SD, McGregor K, Sechtem U, Silber S, Tendera M, Widimsky P, Zamorano JL, Kjeldsen SE, Erdine S, Narkiewicz K, Kiowski W, gabiti-Rosei E, Ambrosioni E, Cifkova R, Dominiczak A, Fagard R, Heagerty AM, Laurent S, Lindholm LH, Mancia G, Manolis A, Nilsson PM, Redon J, Schmieder RE, Struijker-Boudier HA, Viigimaa M, Filippatos G, Adamopoulos S, gabiti-Rosei E, Ambrosioni E, Bertomeu V, Clement D, Erdine S, Farsang C, Gaita D, Kiowski W, Lip G, Mallion JM, Manolis AJ, Nilsson PM, O'Brien E, Ponikowski P, Redon J, Ruschitzka F, Tamargo J, van ZP, Viigimaa M, Waeber B, Williams B, Zamorano JLThe task force for the management of arterial hypertension of the European Society of Hypertension, and The task force for the management of arterial hypertension of the European Society of Cardiology. 2007 Guidelines for the management of arterial hypertension: The Task Force for the Management of Arterial Hypertension of the European Society of Hypertension (ESH) and of the European Society of Cardiology (ESC). Eur Heart $J$ 2007: 28: 1462-1536

28 Rossi P, Frances $Y$, Kingwell BA, Ahimastos AA. Gender differences in artery wall biomechanical properties throughout life. J Hypertens 2011; 29: 1023-1033.

29 Stefanadis C, Tsiamis E, Dernellis J, Toutouzas P. Effect of estrogen on aortic function in postmenopausal women. Am J Physiol 1999; 276: H658-H662.

30 Pearson LJ, Yandle TG, Nicholls MG, Evans JJ. Regulation of endothelin-1 release from human endothelial cells by sex steroids and angiotensin-II. Peptides 2008; 29: 1057-1061.

31 Stauffer BL, Westby CM, Greiner JJ, Van Guilder GP, DeSouza CA. Sex differences in endothelin-1-mediated vasoconstrictor tone in middle-aged and older adults. $\mathrm{Am} \mathrm{J}$ Physiol Regul Integr Comp Physiol 2010; 298: R261-R265.

32 Heintz B, Dorr R, Gillessen T, Walkenhorst F, Krebs W, Hanrath P, Sieberth HG Do arterial endothelin 1 levels affect local arterial stiffness? Am Heart J 1993; 126: 987-989.
33 Vuurmans TJ, Boer P, Koomans HA. Effects of endothelin-1 and endothelin-1 receptor blockade on cardiac output, aortic pressure, and pulse wave velocity in humans. Hypertension 2003; 41: 1253-1258.

34 McEniery CM, Yasmin, Hall IR, Qasem A, Wilkinson IB, Cockcroft JR. Normal vascular aging: differential effects on wave reflection and aortic pulse wave velocity: the AngloCardiff Collaborative Trial (ACCT). J Am Coll Cardiol 2005; 46: 1753-1760.

35 Lieber A, Millasseau S, Bourhis L, Blacher J, Protogerou A, Levy BI, Safar ME. Aortic wave reflection in women and men. Am J Physiol Heart Circ Physiol 2010; 299: $\mathrm{H} 236-\mathrm{H} 242$.

36 Vermeersch SJ, Rietzschel ER, De Buyzere ML, De BD, De BG, Van Bortel LM, Gillebert TC, Verdonck PR, Segers P. Age and gender related patterns in carotid-femoral PWV and carotid and femoral stiffness in a large healthy, middle-aged population. J Hypertens 2008; 26: 1411-1419.

37 The Reference Values for Arterial Stiffness Collaboration. Determinants of pulse wave velocity in healthy people and in the presence of cardiovascular risk factors: 'establishing normal and reference values'. Eur Heart J 2010; 31: 2338-2350.

38 Staessen JA, van der Heijden-Spek JJ, Safar ME, Den HE, Gasowski J, Fagard RH, Wang JG, Boudier HA, Van Bortel LM. Menopause and the characteristics of the large arteries in a population study. J Hum Hypertens 2001; 15: 511-518.

39 Albaladejo P, Laurent P, Pannier B, Achimastos A, Safar M, Benetos A. Influence of sex on the relation between heart rate and aortic stiffness. J Hypertens 2003; 21: 555-562.

40 Mitchell GF, Hwang SJ, Vasan RS, Larson MG, Pencina MJ, Hamburg NM, Vita JA, Levy D, Benjamin EJ. Arterial stiffness and cardiovascular events: the framingham heart study. Circulation 2010; 121: 505-511.

41 Vlachopoulos C, Aznaouridis K, Stefanadis C. Prediction of cardiovascular events and all-cause mortality with arterial stiffness: a systematic review and meta-analysis. J Am Coll Cardiol 2010; 55: 1318-1327.

42 Cecelja M, Chowienczyk P. Dissociation of aortic pulse wave velocity with risk factors for cardiovascular disease other than hypertension: a systematic review. Hypertension 2009; 54: 1328-1336.

43 Rassaf T, Lauer T, Heiss C, Balzer J, Mangold S, Leyendecker T, Rottler J, Drexhage C, Meyer C, Kelm M. Nitric oxide synthase-derived plasma nitrite predicts exercise capacity. Br J Sports Med 2007; 41: 669-673.

44 Wilkinson IB, MacCallum H, Cockcroft JR, Webb DJ. Inhibition of basal nitric oxide synthesis increases aortic augmentation index and pulse wave velocity in vivo. Br J Clin Pharmacol 2002; 53: 189-192.

45 Hayward CS, Kelly RP. Gender-related differences in the central arterial pressure waveform. J Am Coll Cardiol 1997; 30: 1863-1871.

46 Shim CY, Park S, Choi D, Yang WI, Cho IJ, Choi EY, Chung N, Ha JW. Sex differences in central hemodynamics and their relationship to left ventricular diastolic function. J Am Coll Cardiol 2011; 57: 1226-1233.

47 Gatzka CD, Kingwell BA, Cameron JD, Berry KL, Liang YL, Dewar EM, Reid CM, Jennings GL, Dart AM. Gender differences in the timing of arterial wave reflection beyond differences in body height. J Hypertens 2001; 19: 2197-2203.

48 Ayer JG, Harmer JA, Marks GB, Avolio A, Celermajer DS. Central arterial pulse wave augmentation is greater in girls than boys, independent of height. $J$ Hypertens 2010; 28: 306-313.

49 Cecelja M, Jiang B, McNeill K, Kato B, Ritter J, Spector T, Chowienczyk P. Increased wave reflection rather than central arterial stiffness is the main determinant of raised pulse pressure in women and relates to mismatch in arterial dimensions: a twin study. J Am Coll Cardiol 2009; 54: 695-703.

50 London GM, Guerin AP, Pannier B, Marchais SJ, Stimpel M. Influence of sex on arterial hemodynamics and blood pressure. Role of body height. Hypertension 1995; 26 : 514-519.

51 Collis T, Devereux RB, Roman MJ, de SG, Yeh J, Howard BV, Fabsitz RR, Welty TK. Relations of stroke volume and cardiac output to body composition: the strong heart study. Circulation 2001; 103: 820-825.

52 Chemla D, Nitenberg A, Teboul JL, Richard C, Monnet X, le CH, Valensi P, Brahimi M. Subendocardial viability ratio estimated by arterial tonometry: a critical evaluation in elderly hypertensive patients with increased aortic stiffness. Clin Exp Pharmacol Physiol 2008; 35: 909-915.

53 Prince CT, Secrest AM, Mackey RH, Arena VC, Kingsley LA, Orchard TJ. Augmentation pressure and subendocardial viability ratio are associated with microalbuminuria and with poor renal function in type 1 diabetes. Diab Vasc Dis Res 2010; 7: 216-224.

54 Noon JP, Trischuk TC, Gaucher SA, Galante S, Scott RL. The effect of age and gender on arterial stiffness in healthy Caucasian Canadians. J Clin Nurs 2008; 17: 2311-2317

Supplementary Information accompanies the paper on Hypertension Research website (http://www.nature.com/hr) 